\title{
Elaborating population health inequalities in the United States: maternity care in the era of free market system of neoliberalization
}

\begin{abstract}
While there is an extensive array of literature examining the impacts of neoliberal markets on population health and social outcomes, few studies have focused on the impact of neoliberalism on maternity care and women's health in the United States. We provided a critical review of the literature by examining mechanisms linking the emergent neoliberal market systems to maternity care, infant health and women's health outcomes while assessing the population-wide shifts in risk exposures associated with contexts of emergent neoliberalized markets in the country over the last thirty years. The findings from studies showed a correlated pattern of increasing poor health outcomes among women in the United States compared with other industrialized countries over the past three decades. Overall, the health system in the country does not make provisions for some of the most important determinants occurring prior to pregnancy, and often fails to place these concerns in the context of women's health across the life course. Increasing medicalization of pregnancy and birthing processes reflect a dominance of the market-oriented approach of the country's health system. We conclude that many aspects of the emergent neoliberal market influences bear greatly on maternity care and women's health in particular. We further propose that it is only the collective decisions of society (particularly governments at different levels) that can consciously redirect and modify policy interventions to benefit women over the life course rather than on specific periods of pregnancy and childbirth.
\end{abstract}

Keywords: neoliberalization, neoliberal ideology, IMR, LB, CS, MDGs, ACA
Volume 4 Issue 3 - 2018

\author{
Stephen Nkansah-Amankra,' Abdoulaye \\ Diedhiou, ${ }^{2}$ Justin Mendoza ${ }^{3}$ \\ 'Department of Health Services \& Promotion, College of Health \\ Sciences, Sam Houston State University, USA \\ ${ }^{2}$ Core for Applied Research \& Evaluation, Arnold School of \\ Public Health, University of South Carolina, USA \\ ${ }^{3}$ Partners In Health, Boston, USA
}

\begin{abstract}
Correspondence: Stephen Nkansah-Amankra, Department of Health Services \& Promotion, College of Health Sciences, Sam Houston State University, 432I CHSS Building, Huntsville, TX 7734I, USA, Tel 93629427I8, Email sxn017@shsu.edu
\end{abstract}

Received: March 26, 2018| Published: May 18, 2018

\section{Introduction}

An extensive array of literature has examined the impact of neoliberal market policies on population health and social outcomes in the past three decades in the United States and elsewhere. ${ }^{1-5}$ A quick assessment of the literature would show a net negative effect on health and social outcomes. However, few studies have examined the impact of neoliberalism on maternal and women's health in the United States, focusing instead on investigating maternal health and maternity care in other regions of the world. ${ }^{1}$ Complications and concordant health conditions during pregnancy are major life changing experiences for over four million mothers and families annually in the United States. ${ }^{2,6}$ Although these are often considered 'private matters' for women and their families they have become very prominent in public policy discourse given the escalating cost of childbirth and worsening of women's health in the country. ${ }^{7}$ While there is little consensus among scholars on how best to apply public policy to address women's health issues, there is an ongoing debate that the dominant neoliberal market economy has eroded social resources and safeguards for women living in poverty. ${ }^{8-11}$ However, numerous studies have shown availability of social services, including creating public sector jobs, has been a stronger predictor for women's health outcomes than for men. ${ }^{12-14}$

Unfortunately, the general public and health professionals are often not aware of 'the shifting sands beneath our feet' regarding the nature of the emergent neoliberalism and changing socio-political landscapes of the public's health in the country. Over the past three decades, restructuring of welfare as workfare, increased healthcare expenditure and soaring health disparities, resulting in emerging prominence of poor health outcomes among disadvantaged population groups can be correlated with the type of political context that has emerged in the country..$^{2-5}$ For example, income inequality has widened to such an extent that the top one percent of American earners currently receive $22 \%$ of pretax income. ${ }^{15,16}$ The coinciding trends of adopting neoliberal economic policies and the general decline of social and population health outcomes in the country over the period provide an important context for assessing the linkages between emergent neoliberalism and its' impact on maternal and women's health. Unfortunately, the majority of public health and social policies ignores the importance of these economic trends when assessing population health and wellbeing. $5,17,18,19$

The aim of this paper is to review the evidence for associations of the emergent market systems (neoliberalism) as major contextual determinants of maternity care, infants' health and specific women's health indicators in the U.S. applying with population-based prevention strategies as proposed by Rose. ${ }^{20,21}$ We first present the evidence for the association between the emergent markets (neoliberalization) and maternity care; assess some indicators of women's health outcomes in the context of Geoffrey Rose's concept of population-based prevention. ${ }^{20,21}$ Next, we analyze the nature of the emergent market systems, social context of population health, and the challenges facing the U.S. healthcare system. Finally, we discuss interrelated issues linked to maternity care and women's health by demonstrating how the emergence of neoliberal economic policy greatly shapes maternity care, delivery, and pregnancy outcomes in the country. We conclude with discussion of the implications of these findings for public policy, research, and healthcare design. 
Despite its widespread use in the scholarly literature, the term neoliberalism is not easily defined in part because the term reflects a complex blend of ideology, institutional reforms and economic policies. However, neoliberalism is an ideology of free market capitalism extended through market-based competitiveness and commodification of previously protected public goods and populations services. ${ }^{4,5,23}$ This market discipline extends to state institutions in different policy arenas including labor, monetary systems, social protections, education, housing, health. ${ }^{15,16}$ Neoliberal ideology asserts the supremacy of individual action against collective social responsibility. The ideology is conceptualized as limited government responses to the socio-political processes of the nation. In particular, a government's involvement in regulating markets in a neoliberal regime is considered unwanted state interference and often viewed as intrusion into private lives of the citizenry. Neoliberalism is also described as anti-social in terms of socioeconomic policy reforms that would benefit marginalized populations.

To describe the process of transition into a neoliberal-dominated market economy, we used the term neoliberalization. An overwhelming consensus expressed by many scholars is that the emergence of neoliberalism has eroded numerous gains made in publicly supported social interventions in health and social welfare. Neoliberalism as an ideology opposes government interference in markets, which is easily reflected in much of the American health care system. Understanding this is useful because the context by which public policy operates to influence population health is directly lined to political ideology and bureaucratic transformations of governments. ${ }^{24}$ Evidence that neoliberal economic policies have had adverse consequences for health and social wellbeing is incontrovertible in numerous studies, ${ }^{2,3,4,26}$ but the extent to which these differentially translate to poor maternal and child health outcomes in the United States remains unclear. As an economic regime, neoliberalism emerged in much of the industrialized world towards the latter part of the 1960's and early 1970's in response to stagnation and inflation of world economies induced by the oil crisis. Neoliberal economic policy and governance systems first emerged in the U.S. in the latter part of the 1970s around the election of Ronald Reagan as 40th president. Reagan vigorously applied neoliberal ethos in all areas of public policy including education, health, labor relations, social services and many more but greatly supported affluent business groups to manage cheap labor supply as well as providing favorable tax waivers. ${ }^{26}$ This shift in policy discourse affected many facets of wellbeing and social outcomes. Consequently, the organized labor, which hitherto has been crucial in constraining income earning differentials in jobs and advocating for redistributive policies, faced neoliberal onslaught on its ability to mobilize communities on important women's issues including paid maternity leave. ${ }^{12}$ Our primary thesis is that the gradual shift to a neoliberal subordination of collective responsibility (inherent in primary prevention) to an individual's responsibility (a core value in the current market systems) created more risk exposures, to differentially impact on women's health. Within neoliberal market environments, a major explanatory stream for poor population health is increasing income inequality and denial of social safety nets to vulnerable populations. ${ }^{3,27}$ Income or wealth inequalities across states, counties and geographic census tracts are strong predictors of low birth weight, preterm births, maternal mortality and perinatal poor health. ${ }^{3,28}$

Public health principles of population-based prevention embodied in the seminal work of Geoffrey Rose ${ }^{20,22}$ distinguishes risk exposure variations for individuals and variations across the whole population. According to Rose, assessing risk exposures across population groups provides an in-depth understanding of disease etiologies for highrisk individuals. ${ }^{22}$ This is particularly important for groups whose shared social and historical experiences make them highly prone to disease exposures and ill health than the average population. ${ }^{29,30}$ Furthermore, the life course perspective of women's health suggest social, economic, political and legal forces uniquely shape women's health through influences on education, reproduction, social services, family composition and household socioeconomic status. ${ }^{31}$ These forces contribute to women's predisposition to poor health through gender-based embedded beliefs and health behaviors, limited access to healthcare from childbirth to adulthood. Although Rose did not explicitly state the factors of social determinants of health or emerging markets as a major driving force for sick populations, his concept of population exposures leading to emergence of high-risk individuals is self-evident. We revisit Geoffrey Rose's concept of population risk exposures and emergence of sick individuals in the light of increasing evidence that individuals characteristics interacts positively with market systems to shape maternity care outcomes in the United States. ${ }^{2,15,16}$ According to Rose, focusing on high risk individuals alone (typical of the emerging markets style of individualism) to prevent diseases in a population yields limited benefits compared to applying preventive interventions across the whole population instead of targeting individuals. ${ }^{22}$ This understanding further alerts the public's attention to early warnings reflecting changes in risk exposures and poor health outcomes observed only at the population level. ${ }^{32}$

\section{Neoliberalism and population health in the U.S}

The dominance of neoliberal ethos also reflects a conversion of market virtues to individual competitiveness, deregulation, privatization, commodification of public goods and other forms of social disengagement to a variegated global environment. The market virtues associated with the emergence of neoliberalism have generally decimated the Keynesian welfare model, which has been a major socio-economic system in many industrialized countries since the Second World War. A defining moment of neoliberalization occurred with the ascendance of Ronald Reagan as President of the U.S. (19811989) and Margaret Thatcher as the Prime Minister of the United Kingdom (from 1979-1991). Both regimes, considered as vanguards of neoliberalism pursued economic liberalization, privatization of state institutions, and deregulation of public policies impeding corporate capital accumulation, fragmented labor and eroded social entitlements. ${ }^{23}$

These efforts are intended to assert the primacy of competitive markets as the 'engine of economic growth' as well as to rollback the frontiers of the Keynesian welfare model. According to Abramovitz, ${ }^{1}$ The New Right attack on welfare was a strategy to redistribute wealth to the upper echelon of society. The gradual dismemberment of the welfare state and commodification of health care and other social safety nets thus provides a cogent framework to analyze the emergence of poor maternal and child health outcomes in the country. From the era of "New Deal" to "the Great Society", the federal government's support, entitlements and services to families guaranteed some minimum standards of living and family stability. The Keynesian model of welfare thus sustained poor families and women, providing them with more safety nets against the vagxaries of the emerging market ${ }^{1}$ under neoliberalization. Neoliberalism on 
the other hand brought about major shifts in the economic status of women, and simultaneously has created a gap in funding for essential welfare services. In addition to these funding gaps, there has been a decrease in public sector jobs. ${ }^{33}$ These decreases have had detrimental effects on both women's employment and support systems for the unemployed..$^{34}$ Low income, single mothers' employment has dropped precipitously, even lower than overall employment rates in 2000. In addition, the funding for services targeted at mothers has lowered since 2003 to record levels. ${ }^{33}$ Studies also acknowledge that with each of these systems collapsing at gradually, it is less surprising population health outcomes of the most vulnerable populations are adversely affected. For example, following the collapse of communism neoliberal market has dominated countries previously under state regulated the market systems, however the global financial crisis and credit crunch in 2008 brought to the forefront dangers of relying on markets with limited public intervention. These crises also led to an emergent health system shock, resulting in dramatic cuts in public expenditure on health, although these shocks were not due to health system failures. Finally, these cuts greatly destabilized the health of the most vulnerable populations in many industrialized countries. ${ }^{35}$

Undeniably, federal government's supported public health interventions over the past century have led to improved population health outcomes; unfortunately, these gains have not been translated equitably to all populations in the country. ${ }^{29,36}$ Substantial evidence also suggests that increased life expectancy alone is not commensurate with good quality health indicator reporting. As described, a growing literature also suggests public health and other social policies have neglected the role of the neoliberal paradigm as a determinant of health for vulnerable populations and have ignored women's health in this context in particular. ${ }^{4,37}$ In this analysis, we argue that this in part reflects an unfavorable attitude towards social programs paired with an increased skepticism about the role of government engendered by emergent neoliberal market environment. A related consequence is growing wealth and health inequalities over the past three decades in the U.S. and other countries. Even though these inequalities have been occurring in the past decades, much of the public health literature continues to downplay the important role of social contexts in preference to a risk-based approach as a dominant model of curative and preventive care rather than population-based strategies., ${ }^{4,22}$ These relationships are best captured by applying Geoffrey Rose's concept of causes of diseases at the individual level and "causes of the causes" at the population level. Overall, Rose showed through a series of systematic investigations of cardiovascular diseases that risk for hypertension or coronary heart disease at the population level is completely different from risks at the individual level. ${ }^{20} \mathrm{He}$ argued that the distribution of individual risks in the population is a consequence of societal forces acting on the whole population and that the context of individual's risks and diseases is meaningful when the whole population is considered. ${ }^{22}$ Just as Rose showed that it is almost impossible to demonstrate any relationship between salt intake or saturated fat consumption and cardiovascular diseases at the individual level, it may be equally daunting to find relationships between emergent neoliberal socio-political economic systems and health at the individual level in any given population. Thus, "determinants of incidence are not necessarily the same as causes of cases" ${ }^{20}$ in the emergent market economy for individual women or as a population group.

Corollary shifts from public investments in social programs for maternity care, women, children and other vulnerable groups to private enterprise have raised considerable doubts on successful improvement in health and social outcomes of women in the United States and other countries adhering to neoliberal systems of governance. This shift has undermined the public health infrastructure to deliver interventions at multiple levels across the life course of many women.$^{38}$ Rose's analyses of population-based epidemiological strategies to prevention is at odds with neoliberal economic policies, which put more emphasis on applying market principles to meet an individual's needs rather than the social wellbeing of the whole populations. Rose's model encompasses the idea that improved overall population health is more than the sum of improved individual's health outcomes. ${ }^{39}$ This is because risk factors for diseases or mortality are not normally randomly distributed in any given population, but follows a clearly defined pattern of susceptibility that might manifest as high risk groups. ${ }^{40}$ Contextual exposures leading to individual's poor health has a prominent place within Rose's population health prevention strategies, although other investigators have suggested the strategy might create population health inequalities. ${ }^{30}$ The extent to which the market systems put higher emphasis on individual market performance is at odds with Rose's ideals and approach to population health may well explain increased risk exposure among poor individual women, and might also shed light on future directions to correct these exposures.

\section{Challenges of the U.S. public health system, maternity care and neoliberalism}

The health system of the United States is complex and highly fragmented with a myriad of different stakeholders seeking to strengthen their self-interests. ${ }^{41-43}$ This is evident in range of insurance premiums, finances and tremendous resource outlays within the healthcare system. The cost of the U.S. healthcare system is estimated at almost $\$ 3$ trillion in $2001^{42}$ and projected to increase rise to 5.4 trillion a year by $2024 .{ }^{44}$ The federal government's share of the expenditure has increased substantially, more than 10 times since the $1980 \mathrm{~s} .{ }^{45}$ Americans also pay much higher prices for the same health service compared with citizens of other countries. ${ }^{43}$ Despite considerable healthcare resource expenditures, the United States consistently ranks at the bottom of the industrialized world in terms of health outcomes. In 2014, female life expectancy in the United States was the lowest and infant mortality the highest among eight industrialized nations ${ }^{46}$ Furthermore, maternity care and the health of citizens in the country experience disparities across ethnic, class, and socioeconomic lines are considered as unnecessary, unfair and unjust. ${ }^{12}$ The United States is the only industrialized country in the world with no definable national health insurance, and is therefore not surprising that the country ranked $37^{\text {th }}$ the among the OECD countries for life expectancy at birth in 2014 (Figure 1) ${ }^{47}$ Even here there are considerable geographical and racial disparities within the country. The infant mortality rate (IMR) for example in the most deprived region of the country compared with the least deprived ones showed an increasing pattern of 1.43, 1.49 and 1.63 times higher in 1980, 1990 and 2000 respectively. ${ }^{48}$ One report showed the gap in life expectancy between the least deprived and most deprived areas of the United States as widening from 2.8 years in $1980-82$ to 4.5 years in 1998$2000 .{ }^{48}$ Additional statistics show other inequities remain. Infants and maternal deaths are the worst among the industrialized countries of the world, although infant mortality declined by $12 \%$ from 2005-2011 to 6.05 infant deaths per 1000 live births. ${ }^{49}$ Data from the Pregnancy Mortality Surveillance System indicates that the pregnancy related 
mortality ratio dropped from 10.9 per 1000 live births (LB) in 1979 to 7.4 in 1986 and then showed upward rise to 9.1 in 1987-1990, 11.5 in 1991-1997, and 16.8 per 1000 LB in $2003^{50,51}$ While life expectancy has risen in the country overall, in some counties it has actually declined for many women in the past two decades., ${ }^{7}$ The graph below Figure 2 indicates trends in pregnancy-related mortality ratios in the United between 1987-2012. More astonishingly, according to 1990-2008 United Nations data, while maternal deaths decreased by $34 \%$ worldwide, reporting of maternal mortality almost doubled in the United States. ${ }^{53}$ Black women were at almost four times greater risk of maternal deaths than their white counterparts. Overall, the health system in the country does not make provisions for some of the most important determinants occurring prior to pregnancy, and often fails to place these concerns in the context of women's health across the life course. ${ }^{54}$ Wealth inequality in the U.S. has increased over the last

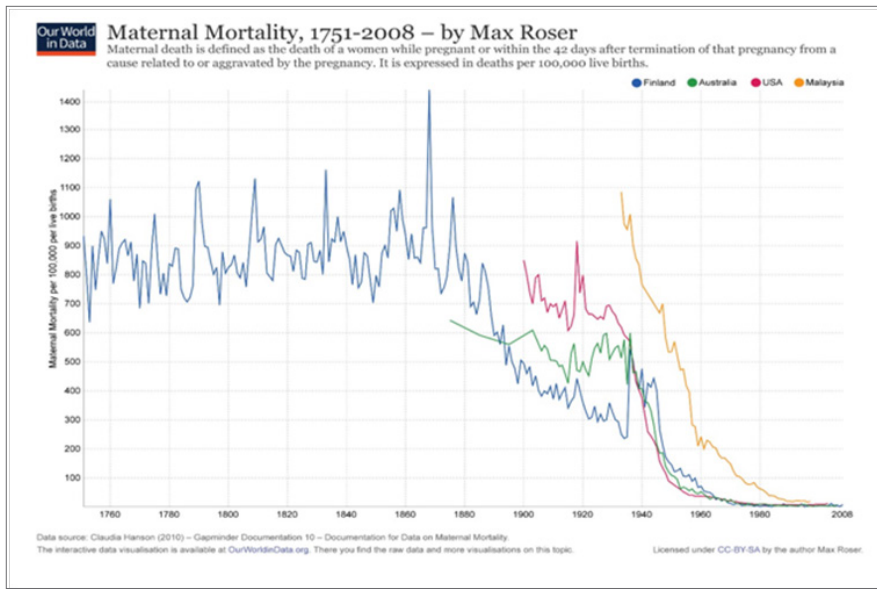

Figure I Maternal mortality in the United States from 1900 compared with other industrialized countries and Malaysia

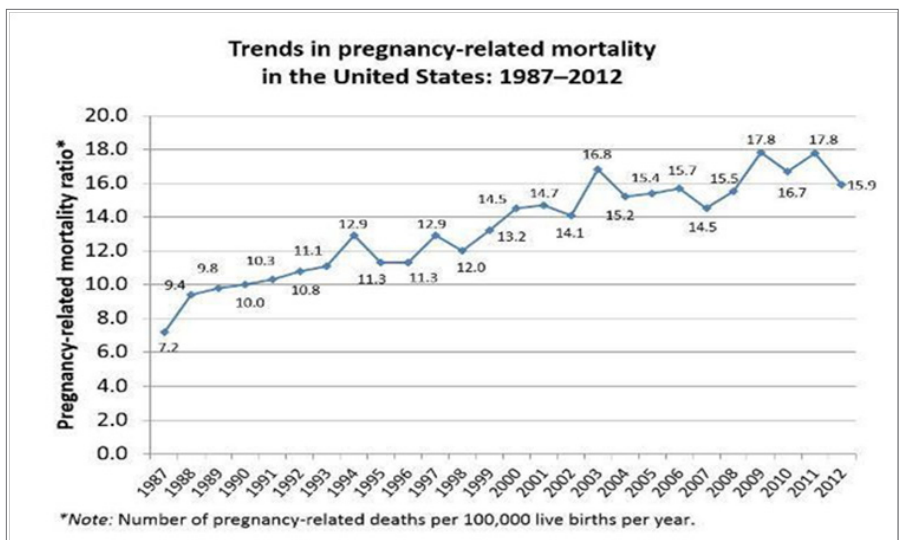

Figure 2 Trends of pregnancy related mortality in the United States

significant rise in cesarean section (CS) rates in the country over the last three decades. The World Health Organization (WHO) suggests the best outcomes for mothers and babies are a CS rate of $5-10 \%$, and a rate above $15 \%$ is harmful..$^{62}$ In the United States in 2003, one mother in three $(32.7 \%)$ gave birth by CS. The overall CS delivery rate increased almost $60 \%$ from 1996-2009 reaching 32.9\% however the rate for black mothers remained unchanged at $35.9 \% .{ }^{63}$ Given that most women in the country are healthy at the time of delivery, there are no clear medical rationales for these increases. In the neoliberal four decades as the real income of the poorer $40 \%$ in the U.S. has declined precipitously, resulting in almost $15.1 \%$ ( $\approx 46$ million people) of the population living in poverty in 2010. As Figure 3 data suggests, the share of before tax income among the richest $1 \%$ has shown significant gains since the latter part of 1970's and currently parallels the level of 1920's. ${ }^{55}$ Another 46million people were either uninsured or underinsured, before implementation of new health care reform laws, which has decreased this number significantly. It is important to examine the context of these statistics. Since the emergence of poor health outcomes associate with the onset of neoliberal economic policies in the U.S. and elsewhere an argument could be made for the occurrence of the widening inequalities in the country. These findings also reflect the weakness of the public health infrastructure not only to support the delivery of the major essential public health services, but in addition to improve specific $\mathrm{MCH}$ outcomes. ${ }^{56}$

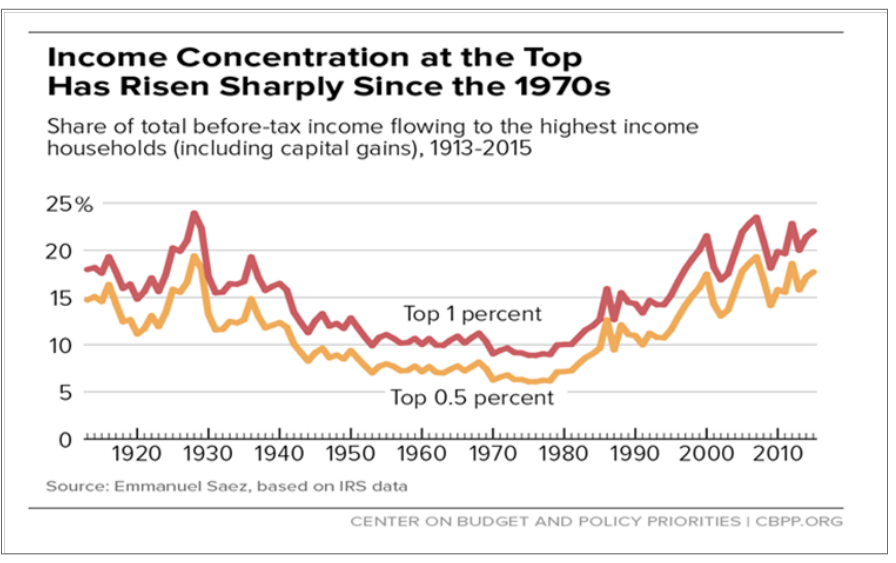

Figure 3 Trends of income inequality across the country from 1920-2010

Neoliberal idealism has also changed the decisions that individuals make in the health care market, as well as which options are presented in the first place. Increasing medicalization of pregnancy and birthing processes, such as requiring sophisticated scientific technologies and specialized aids, is criticized as reflecting a dominance of the market-oriented political economy of the country's health system. ${ }^{2,57}$ This in part reflects the empowered status of medicine in determining a mothers' choice of maternity care and service delivery options..$^{58}$ The overbearing dominance of medicine in the healthcare system is evidenced by creation of rhetoric that natural birthing processes need extraordinary care from a specialist. ${ }^{59-61}$ Even though a large percentage of infants in the country are delivered by uncomplicated vaginal delivery, the use of midwifery services is greatly underutilized. ${ }^{43}$ Within the neoliberal medical model, pregnancy and maternity care are viewed as pathological events needing specialized care. These developments are also accompanied by significant changes in the delivery of maternity care services. One of these changes is the

context, medicine is seen as an applied instrument of social control and increasing medicalization of pregnancy and childbirth reinforces limited choices of birthing mothers. The result is escalating cost of maternity care without commensurate improvement in the health of mothers in the country. ${ }^{57,59,60}$ In addition, much of the focus on women's health is also directed at pregnancy to the neglect of other critical periods of life such as pre-conceptual, inter-conceptual and menopausal periods. This narrow focus thus excludes childless women with other health issues in later years. ${ }^{31}$ 
Further, the health and healthcare strategies in the country are intricately linked to the political structure and culture of the American exceptionalism. These systems including political structure (divided government, federalism and weak national political systems), along with a culture of strong protection of private interests and a population suspicious of a government's intervention, have reinforced the direction of healthcare in neoliberal periods. ${ }^{64}$ These political influences are reflected in the history of the Medicare program in the United States since the passing of the bill in $1966 .{ }^{65}$ A lack of strong organized labor and persistent political influences of interest groups linked to the market systems have combined to derail attempts of the federal government to take collective responsibility for the overall population health and a health insurance option in particular for the country. Evidence from Tope and Jacobs' historical data analysis shows that traditionally unions have been vanguards for public policies particularly those serving great interests of vulnerable and less privileged populations, ${ }^{66}$ yet the U.S. labor movement has decreased in size and influence in the era of neoliberalism..$^{24,66,67}$

To sum, numerous studies show that by population health indicators, the United States ranks far lower than almost all countries belonging to the Organization of Economic Cooperation and Development -OECD. ${ }^{15}$ More intriguing is the revelation that declining population health emerged in the latter part of 1970's, a period that also coincides with the dominance of neoliberal economic governance in the country. ${ }^{67}$ It is obvious that the wider determinants of these are directly linked to the socio-political systems disinvesting in social programs to the detriment of vulnerable population groups likely to benefit from such public support. ${ }^{26}$ The challenge for the public health system in the United States is to re-focus on Rose's population level prevention strategies of identifying higher number of people at low risk vs. low number high risk individuals.

\section{Neoliberalism, maternity care, personal responsibility and increasing health inequalities}

The above analysis suggests the emergent neoliberal market in the socio-political landscape is associated with marked differences in population health in the United States, and women are more likely to be affected negatively. These are not simply the result of a series of disconnected individual's behaviors over time, ${ }^{50}$ but are largely congruent with adoption of neoliberal political ethos of governance, in both republican and democratic administrations ${ }^{68}$ Indeed, the notion of personal responsibility for health in the face of enormous socio-cultural challenges including poverty, lack of insurance, unemployment, nonexisting social supports, social networks or social exclusion and gender status is described as façade by many health scholars. ${ }^{4,39,69,70}$ In actuality, the idea of personal responsibility for health ignores the complex interactions of the role of broader social contexts for making decisions on health or to engaging in health related behaviors. Most women in poverty or living in deprived communities have little or no control on the environmental factors affecting personal health behaviors and circumstances of their pregnancies. However, a renewed emphasis on personal responsibility for health greatly cohere with emerging neoliberal proclivity of holding individuals responsible for their health behaviors and ill-health. This attitude thus ignores governments role in mobilizing collective social resources for improved population health and on contrary health and disease becomes the responsibility of individuals. Nonetheless, there have been a range of federal government policy responses and other policy interventions to these negative health outcomes. The Millennium Development Goals (MDGs) of the United Nations called for a 75\% reduction in maternal mortality by 2015 , this was not met globally. The Healthy People 2010 and the follow up

Healthy People 2020 policy documents also called for considerable reduction of women who die during childbirth and pregnancy. Even though some progress has been reported, the general trend is that these targets are unlikely to be met. A report by Amnesty International, ${ }^{71}$ "Deadly delivery", described maternal deaths in the United States as a serious scandal. A major policy response from the federal government to improve population healthcare is enactment of "The Patient Protection and Affordable Care Act of 2010 (ACA)." This legislation promised increased access to preventive healthcare and screening services without an upfront payment for services, however, the law is described as windfall benefitting the insurance including mammograms, screening for cervical cancer, prenatal companies. Under the legislation, women's preventive health services care and pregnancy do not require any form of cost sharing with insurance companies. This means covered women face zero dollars out-of-pocket spending for these services. Based on the policy and implementation guidelines of the ACA, the US Department of Health and Human Services' Assistant Secretary for Planning and Evaluation tasked the Institute of Medicine (IOM) to evaluate recommendations for women's preventive services. ${ }^{72}$ The aim was to guide the development of a comprehensive package of policy and program to be implemented under the ACA. Although this was a laudable effort of the federal government to improve the health care of women in the country, critics point to the process as more treatment-focused approach rather than preventing avoidable health conditions early in the lives of women. To gain some deeper insights on worsening maternal and child health outcomes in the country over time, it is pertinent to revisit the question Rose asked in his paper: "Why did this person, get this disease at this time?" This could be asked differently as: "Why is the United States recording worsening maternal and child health outcomes at this time?" To answer these questions requires careful analyses of major socio-political exposures leading to the emergence of high risk individuals' maternal health care outcomes. It also requires deeper understanding, as Sakala \& Correy, ${ }^{6}$ explains, "effective maternal care with least harm is optimal for childbearing women and newborns." Inequities in health have been a longstanding social issue in the country greatly influenced by key political agendas and sectional interests linked to neoliberal market forces. ${ }^{22,58,73}$ Yet it is important to recognize the socio-political developments that occurred prior to the passing of the law, which mandates increased access to health insurance in the country.

At the beginning of the 20th century, federal and state publicly funded health programs were mainly instituted to target periods of pregnancy, postpartum care and childcare. These policies missed inter-conceptual periods and prior pregnancy periods despite higher maternal mortality and morbidity in the country. During this era of policymaking, the focus was on improving the wellbeing of children as future leaders, workers, and parents of the country. A major challenge was the increased recognition that the hazardous working conditions of children posed considerable threats to their educational and social developments. Maternal and women's health issues became peripheral to improved infant and childhood wellbeing. ${ }^{74}$ The assumption during this time was that improving child health outcomes improves maternal health, and this idea underpinned all federal and 
state support on health programs. ${ }^{75}$ One of the earliest legislation specifically targeting the health and wellbeing of women and mothers in 1918 was strongly opposed for reasons of inappropriate institutional placement by opponents. ${ }^{76}$ The Sheppard-Towner Act of 1921 was the first progressive agenda focusing on health and social wellbeing of women, mothers and maternity care in the country. ${ }^{77}$ This Act was the first of its kind to build the Maternal and Child Health infrastructure in the country. However, the Act was vigorously assailed by various interest groups as a threat to American democracy, a form of socialized medicine and a violation of constitutional rights. Core to these criticisms was the feeling of overreach by the federal government in the lives of women and mothers. When the Act was repealed in 1929 , maternal death rates had reduced from about 68 per $1000 \mathrm{LB}$ in 1921 to 62 per $1000 \mathrm{LB}$ in $1927 .{ }^{77}$ Subsequent consideration of maternal and infancy care came with the emerging developments of the social security legislation of the 'New Deal' in 1935. The Social Security Act of 1935 includes public assistance, Aid to Dependent Children and the enactment of Title V (currently administered by the Health Resources and Services Administration, Department of Health and Human Services). The opponents of welfare characterized the program as incipient socialism, and women recipients became the assailable character in the 1960s. These patterns demonstrate the important roles of socio-political forces of governments in shaping the population health outlook particularly for women and other vulnerable populations. ${ }^{70}$ However, in the U.S. and Britain, the adoption of neoliberal political ethos by neoconservative governments of respective countries was followed with the revival of some of the 19th century Victorian era moral values and controls. ${ }^{78}$ This attitude was further exemplified as a major challenge to women's health when neoconservatives in the 1980's attempted to deny women's rights to sexual and reproductive health services in the country, even though the Roe vs. Wade verdict of the US Supreme Court had legalized abortion in 1973.

Fine \& McClelland ${ }^{10,11}$ have argued that eroding state resources for health and social programs undermined women's sexual wellbeing. We propose that the neoliberal rhetoric of personal responsibility and self-determination is at least in part to blame for public perception around abortion decisions. The individual responsibility engrained in neoliberal ethos is one factor that leads many women to selfblame in situations of sexual vulnerability and as victims of male sexual aggressions. Women's behaviors in these circumstances are constructed as an individual's choices and thus leave the broader society to conclude that poor health is the result of poorly informed decisions, ignoring underlying social contexts and interrelated factors, which contribute greatly to these decisions. Market fundamentalism now represents a system for restructuring state institutions that used to provide social and economic protections for vulnerable populations at the national level and shifting these responsibilities to local entities. ${ }^{79}$ The devolution has shifted responsibility for social wellbeing to individuals and households, thereby undermining the idea of collective responsibility for population health. Indeed, for many Americans health is seen as more of an individual's responsibility rather than as collective responsibility of the broader society and its political institutions. Finally, many American citizens, including health professionals, do not readily grasp the notion that root causes of health inequalities are deeply embedded in the American societal structures and institutions. ${ }^{15}$ To sum up, the observed cases reflect patterns of neoliberal public policy decisions and ideals affecting overall health and wellbeing of women and children.

\section{Welfare and maternal health in the era of neoliberalization}

Provision of social welfare has been an integral part of the American values since the establishment of the colonies ${ }^{80}$ Consistent with this historical antecedent, the welfare state is expected to provide its citizens with economic security and social protections against uncertainties or calamities emerging from the operation of capitalism. Originally, this was intended to improve the wellbeing of deprived and marginalized populations of the society.

However, the emergence of neoliberalism has created a system in which welfare recipients are often disparaged as the undeserving poor and met with hostility. ${ }^{81}$ During the Progressive Era of the 1930 's, welfare was perceived as more than relief. Welfare was seen as a form of economic security or buffer for population wellbeing. Critical areas of economic security included unemployment, old age, sickness and expanded healthcare costs..$^{79,81-83}$ The neoliberal paradigm ended the historical standard for American social welfare, with President Clinton signing into law the Personal Responsibility and Work Opportunity Reconciliation Act (PRWORA) in 1996. The consequence was lowered funding in welfare systems for women, along with stark declines in public sector jobs. These changes have created entry points for many women 'to go into and stay' in poverty. ${ }^{84}$ Government rollbacks have also cut funding in education and health services aimed at helping women and children..$^{33,85-87}$ Welfare historian Michael Katz, ${ }^{81}$ points out that the history of the rates of women in poverty has stayed consistent over the years and welfare systems in the country have consistently failed to increase the income of mothers and women at large over time. ${ }^{88}$ Further, Katz ${ }^{81}$ points out that societal issues with the welfare state in labeling people as the "undeserving poor' based on moral objections to the use of public benefits and in the process classify single, unemployed mothers as a prime 'undeserving' poor. The stigma towards beneficiaries has drawn the United States into imposing reforms of instilling 'workfare' where people are required to work whilst receiving benefits, rather than welfare systems without the means-testing for recipient population ${ }^{79,81}$

Esping-Andersen ${ }^{89}$ has demonstrated that welfare-state regimes (although a contested term) are important determinants of human health and distribution of social wellbeing but are often in direct conflict with the prevailing market systems. The clustered typologies of welfare regime types; conservative, liberal and social democratic; may also represent a system mix directly linked to a country's social policy and contexts of political economy. The mix in the U.S, includes an increased role of private insurance markets and publicly financed Medicare and Medicaid programs. These typologies, categorized on principles of decommodification (reliance on market determinants), social stratification (roles of the welfare states in creating or removing unequal positioning of subgroups) and the private-public mix (relative roles of states, groups, families and markets in the welfare state), serve as the main systems for the "production and distribution of social wellbeing." ${ }^{\circ 9}$ Although these typologies have been criticized among others as being 'gender-blind' in regards to analyses of women's unpaid family care and reproduction, ${ }^{90,91}$ they provide a reasonable basis for understanding distinct pathways leading to the emergence of different modern welfare nations ${ }^{92}$ and how these have been greatly influenced by political ideologues. The United States provides minimal welfare benefits and social insurance contingent on means testing, but importantly the system disregards gender and unique needs of women in particular. ${ }^{93}$ Some scholars assert that the 
original idea of the US welfare system appears to be targeting males to provide transient support as a way out of poverty. ${ }^{39,70}$ In this regard, the needs of single mothers including child support was not factored into the original design of the welfare program. According to Katz, the 'end of welfare' in the United States signaled a great triumph for three great forces: the war on dependence, the devolution of public policy, and the commodification of public policy. ${ }^{81}$ The switch from the 'war on poverty' to 'war on welfare' led to reform policies that required working commitments of mothers. Since most women who take in benefits were unemployed mothers, this immediately took away from the support system for many of the country's most vulnerable populations. It is also important to note that the discriminatory practices of the welfare program from the outset towards people of color denied these families the needed resources and support.

\section{Contextualizing discourse of neoliberalization and women's health}

In this section, we examine how women assessed both as individuals and collectively exposed to risk factors of diseases, illhealth, and poverty since the ascendance of neoliberalism in the United States. According to Link \& Phelan, $, 44,95$ one of the fundamental causes of diseases linked to social conditions involve denial of access to resources assisting individuals and groups to avoid exposure to health risks. Analyses of the framework suggest even when disease conditions or individually focused behaviors are modified, to eradicate diseases or adverse social conditions, the relationship between the disease or the social ill-health and the fundamental social factors would "re-emerge". Link \& Phelan ${ }^{94}$ thus the authors assert insofar as the fundamental causes linking behaviors or diseases to a particular social condition endures, efforts to eliminate the intermediate links would not yield desirable outcomes. In other words, to address major discrepancies in health outcomes, change in the social determinants of health is necessary for lasting change. Importantly, relationships among social conditions and patterning of diseases ${ }^{96}$ are modified by the availability of resources ${ }^{95}$ on "human-directed agency." Humandirected agency in neoliberal discourse asserts self-determination, informed or free choice as inherent values of personal responsibility. Additionally, neoliberalism erodes social and environmental resources through government cuts in safety and regulatory standards, labor deregulation and disinvestments in publicly subsidized goods and services. Each of these key areas of public policy provides a contextualized impact on human behavior. ${ }^{5,8}$ Understanding the context of neoliberalization as systems of influences on human behaviors (particularly for women) provide contexts for understanding how relationships of human behaviors are shaped or influenced by the unique socio-political processes. Indeed, human behavior cannot be solely attributable to an individual's responsibility and choice, ${ }^{69}$ ideas that run counter to the prevailing market systems.

\section{Concluding comments}

Neoliberalism has emerged as a dominant form of socio-political market economy. It reinforces pricing systems for commodifying public goods and accompanying policies that reduce public expenditures on health, education and other social programs. While some have argued that the dominance of neoliberalism has improved efficiency of social systems, the overall evidence suggests this form of market system might have had negative impacts on population health A major critique of neoliberalism is increasing inequalities in health and other social systems as well as medicalization of reproductive lives of women, particularly in the United States. This critique aligns with Rose's population strategy, which presumes that the occurrence of risk exposures is determined by contextual socio-political and economic forces and individual cases emerge as a consequence of average risk exposures of the overall population..$^{57}$ Furthermore, choice as an embedded concept in neoliberalism is problematic due to the uneven distribution of health-enhancing resources across all population groups. Importantly, maternity care decisions are made in the context of the larger social processes shaping choices and pregnancy outcomes. ${ }^{58}$ Rose's analysis of different strategies for improving population health serves as an important heuristic approach for public health interventions to recognize the role of contextual market systems as strong determinants of health for the whole population rather than individuals. This alternative concept of disease causation reflects a complex pattern of underlying social determinants of poor health and other behaviors giving rise to sick individuals. ${ }^{97,30}$ Neoliberal policy regimes have been found to correlate strongly with a series of poor population health outcomes (income inequality, maternal mortality, low birth weight, preterm births, reduced life expectancy) and women's health in particular. ${ }^{14}$ However, it is not always clear the precise mechanism through which neoliberal economic systems influence maternal and child health outcomes.

Neoliberal economic policies emphasize the importance of individualism against claims of collective responsibility, and further co-modifies social relationships as market values and prices. However, individual actors are more complex than simple market actors are, and social influences hold large weight on their behavior and choices. Market deregulation of services, products and business practices result in non-adherence to standards and possibly compromise quality. ${ }^{98}$ A major factor contributing to poor obstetric practice in the country is the absence of national standards for managing obstetric emergencies and complications in maternity care. ${ }^{99}$ Those standards must also reflect benefits to be accrued to women over the life course rather than corporate interests in the healthcare system alone. Changes in social contexts that influence health risks are the most important predominant factors to reducing risk across the whole population rather than isolating individuals at risk for treatment. This requires systems thinking to recognize that declining poor health among specific population groups are consequences of complex interacting socio-political processes since emergence of neoliberal-style of governance.

A key question relates to mechanisms accounting for the effects of disinvestment of social programs on maternity care and long term mental health of women. The welfare state has been under assault with the rise of global capitalism as typified by emergent neoliberalism in the United States and elsewhere. Some scholars have suggested the need to reform social policies, particularly unfair punitive treatment against pregnant women or postpartum mothers who test positive to illegal drugs. ${ }^{100,101}$

Third, identifying high risk individuals for treatment is consistent with the neoliberal focus of individualism and medicalization of health as a commodity. In the United States the high rate of caesarian section applied in maternity care delivery is unnecessary and could be reduced by employing midwifery models of care and appropriate standards of practice. Rose contends that identifying high risk individuals provides motivation for treatment but has very limited application to improved overall population health. ${ }^{20}$ Indeed, the 
lifestyle approach typically used in the medical system may actually exacerbate the existing social gradient in health through benefits accrued to populations in the higher social hierarchy. ${ }^{102}$ This focus thus reinforces the idea of health as a social issue. Because a high risk approach is palliative and temporary, treatment of individuals with low risk might continue almost indefinitely. The underlying causes of these risks as embedded in the societal structures and institutions are managed only superficially. ${ }^{25}$ Given the downstream approach associated with identifying high risk groups, individuals from the whole exposed population will continue to emerge for treatment as a consequence exposure burden on the whole population. This is consistent with the evidence suggesting increased medicalization of maternity care in the United States and elsewhere is directly linked to the variegated forms of intensified market systems. ${ }^{57,103-110}$

Reducing population health inequalities in neoliberal regimes will require increased understanding of societal collective responsibility towards the underlying social determinants of health embedded in societal structures and institutions. The current maternity care practice in the country is disjointed and lacks coherent strategic policy direction ${ }^{111-117}$. The design is more favorable to the interests of corporate bodies than to women and their families. Shifting focus of pregnancy and maternity care as pathological events to natural reproductive events will require changing societal norms and the provision of a high quality primary care system towards collective good of women and their families. More research is needed to recognize the population-based needs of pregnancy and maternity care and the extent to which these reflect the emerging markets among key stakeholders in the healthcare and public sectors. The main policy implication of this paper is that a reversal of neoliberal economic policies as the framework for decisions around maternal and child health would benefit the health outcomes of mothers in children in the United States.

\section{Declarations}

Ethics approval and consent to participate. We consent to ethical standards of the International Committee of Medical Journal Editors (ICMJE) criteria for authorship.

\section{Consent for publication}

We are pleased to submit to your journal for consideration and publication the manuscript.

\section{Acknowledgements}

None.

\section{Conflict of interest}

Author declared there is no conflict of interest.

\section{References}

1. Abramovitz M. Women, social reproduction and the neo-liberal assault on the US welfare state. 2015.

2. Benoit C, Stengel C, Phillips R, et al. Privatization \& marketization of post-birth care: the hidden costs for new mothers. Int $J$ Equity Health. 2012;11:61.

3. Coburn D. Income inequality, social cohesion and the health status of populations: the role of neoliberalism. Soc Sci Med. 2000;51(1):135-146.
4. Navarro V. Neoliberalism as a class ideology; or, the political causes of the growth of inequalities. Int J Health Serv. 2007;37(1):47-62.

5. Peck J, Tickell A. Neoliberalizing space. Antipode. 2002;34(3):380-404.

6. Sakala C, Corry MP. Evidence-based-maternity-care: What is it and what can it achieve. 2008.

7. Kindig DA, Cheng ER. Even as mortality fell in most U.S. counties, female mortality nonetheless rose in $42.8 \%$ of counties from 1992 to 2006. Health Aff. 2013;32(3):451-458.

8. Bay-Chen LY, Eliseo-Arras RK. The making of unwanted sex: Gendered and neoliberal norms in college women's unwanted sexual experiences. $J$ Sex Res. 2008;45(4):386-397.

9. Connell R. Gender, health and theory: Conceptualizing the issue, in local and world perspective. Soc Sci Med. 2012;74(1):1675-1683.

10. Fine M, McClelland SI. Sexuality education and the discourse of desire: Still missing after all these years. Harvard Educational Review. 2006;76(3):297-338.

11. Fine M, McClelland S. The politics of teen women's sexuality: Public policy and the adolescent female body. Emory Law Journal. 2007;56(4):993-1038.

12. Bernhardt A, Dresser L. Why privatizing government services would hurt women workers. Institute for Women's Policy Research; 2002.

13. Denton M, Walters V. Gender differences in structural and behavioral determinants of health: An analysis of the social production of health. Soc Sci Med. 19949;48(9):1211-1235.

14. Wisdom JP, Berlin M, Lapidus JA. Relating health policy to women's health outcome. Soc Sci Med. 2005;61(8):1776-1784.

15. Benzruchka S. American experiences. In: D Raphael, editor. Tackling health inequalities: Lessons from international experiences. Toronto: Canadian Scholars Press Inc; 2012.

16. Hummelstein DU, Woolhandler S. Privatization in a publicly funded healthcare system: The U.S experience. Int J Health Serv. 2008;38(3):407419.

17. Blakely TA, Woodward AJ. Ecological effects in multi-level studies. $J$ EpidemiolCommunity Health. 2000;54(5):367-374.

18. Kramer MS. Invited Commentary: Association between restricted fetal growth andadult chronic disease: Is it causal? Is it important? $\mathrm{Am} J$ Epidemiol.2000;152(7):605-608.

19. Plowright RK, Sokolow SH, Gorman ME, et al. Causal inference indisease ecology: investigating ecological drivers of disease emergence. Frontiers in Ecology and the Environment. 2008;6(8):420-429.

20. Rose G. Sick individuals and sick populations. Int $J$ Epidemiol. 2001;30(3):427-432.

21. Doyle YG, Furey A, Flowers J. Sick individuals and sick populations: 20 years later. J Epidemiol Community Health. 2006;60(5):396-398.

22. Rose G. Strategy of preventive medicine. Oxford University Press Inc: New York; 1992.

23. Harvey B. A brief history of neoliberalism. Oxford University Press: New York; 2005 .

24. Sager T. Neoliberal urban planning policies: A literature survey 19902010. Progress in Planning. 2011;76(4):147-199.

25. Nkansah-Amankra S, Agbanu SK, Miller RJ. Disparities in health, poverty, incarceration, and social justice among racial groups in the United 
States: A critical review of evidence of close links with neoliberalism. Int $J$ Health Serv. 2013;43(2):217-240.

26. Jacobsa D, Myers L. Union strength, neoliberalism, and inequality: Contingent political analyses of U.S. income differences since 1950 American Sociological Review. 2014;79(4):752-774.

27. Tracy M, Kruk M, Harper C, et al. Neoliberal economic practices and population health: a cross-national analysis, 1980-2004. Health Econ Policy Law. 2010;5(2):171-199.

28. Nkansah-Amankra S, Twumasi-Ankra P. Neighborhood poverty, income inequality, and infants' health: Examining the links with the South Carolina PRAMS data, 2000-2003. Journal of Poverty. 2013;17(2):157-176.

29. Frohlich KL, Potvin L. The inequality paradox: The population approach and vulnerable populations. Am J Public Health. 2008;98(2):216-221.

30. McLaren L, McIntyre L, Kirkpatrick S. Rose's population strategy of prevention need not increase social inequalities in health. Int J Epidemiol. 2010;39(2):372-377.

31. Strobino DM, Grason H, Minkovitz C. Charting a course for the future of women's health in the United States: concepts, findings and recommendations. Soc Sci Med 2002;54(5):839-848.

32. Szreter S. The population health approach in perspective. Am J Public Health. 2003;93(3):421-431.

33. Chapman J, Bernstein J. Falling through the safety net: low-income single mothers in the jobless recovery. Economic Policy Institute: Issue Brief; 2003 .

34. Institute for Women's Policy Research. The status of women in the states. Institute for Women's Policy Research: Washington DC; 2000.

35. Mladovsky P, Srivastava D, Cylus J, et al. Health policy responses to the financial crises in Europe. Policy Summary. World Health Organization; 2012

36. Schrecker T, Chapman AR, Labonte R, et al. Advancing health equity in the global marketplace: How human rights can help. Soc Sci Med 2010;71(8):1520-1526.

37. Misra D. Women's Health Data Book: A profile of women's health in the United States. 3rd ed. Jacobs Institute of Women's Health and The Henry J. Kaiser Family Foundation: Washington DC; 2011.

38. Braveman P, Barclay C. Health disparities beginning in childhood: A lifecourse perspective. Pediatrics. 2009;124(Suppl 3):S163-S175.

39. Reidpath D. Population health. More than the sum of the parts? $J$ Epidemiol Community Health. 2005;59(10):877-880.

40. Murray CJ, Atkinson C, Bhalla K, et al. The state of U.S. health, 1990-2010: Burden of diseases, injuries, and risk factors. JAMA. 2013;310(6):591-608.

41. Martin AB, Lassman D, Washington B, et al. Growth in US spending remained slow in 2010; health share of gross domestic product was unchanged from 2009. Health Aff. 2012;31(1):208-209.

42. Reinhardt UE, Hussey PS, Anderson GF. U.S. healthcare spending in an international context. Health Aff. 2004;23(3):10-25.

43. Sisko AM, Truffer CJ, Keehan SP, et al. National health spending projections: The estimated impact of reform through 2019. Health Aff. 2010;29(10):1933-1941.

44. McCarthy M. US healthcare spending will reach $20 \%$ of GDP by 2024 BMJ. 2015;351:4204

45. Turnock BJ. Law, government and public health. In: Burlington MA, editor. Public health: What it is and how it works. Jones \& Bartlett Learning; 2006.

46. Himmelstein DU, Jun M, Busse R, et al. A Comparison of hospital administrative costs in eight nations: US costs exceed all others by far. Health Aff. 2014;33(9):1586-1594.

47. The World Bank. Life expectancy at birth. 2014.

48. Singh GK, Siahpush M. Widening socioeconomic inequalities in US life expectancy, 1980-2000. Int J Epidemiol. 2006;35(4):969-979.

49. Mac Dorman MF, Hoyert DL, Mattehws TJ. Recent declines in infant mortality in the United States, 2005-2011. National Center for Health Statistics; 2013.

50. Berg CJ, Callaghan WM, Syverson C, et al. Pregnancy-related mortality in the United States, 1998 to 2005. Obstet Gynecol. 2010;116(6):13021309.

51. Berg CJ, Chang J, Callaghan WM, et al. Pregnancy-related mortality in the United States, 1991-1997. Obstetrics \& Gynecology. 2003;101(2):289296.

52. Ezzati M, Friedman AB, Kulkarni SC, et al. The reversal of fortunes: trends in county mortality and cross-county mortality disparities in the United States. PLoS Med. 2008;5(4):e66.

53. World Health Organization. Trends in maternal mortality: 1990 to 2008 : Estimates developed by WHO, UNICEF, UNFPA and The World Bank. 2015.

54. Misra DP, Guyer B, Allston A. Integrated perinatal health framework: A multiple determinants model with a life span approach. Am J Prev Med. 2003;25(1):65-75.

55. http://www.cbpp.org/sites/default/files/atoms/files/11-28-11pov_1.pdf

56. Baker EL, Potter MA, Jones DL, et al. The public health infrastructure and our nation's health. Annual Review of Public Health. 2005;26:303-18.

57. Benoit C, Zadoroznyj M, Hallgrimsdottir H, et al. Medical dominance and neoliberalisation in maternal care provision: The evidence from Canada and Australia. Soc Sci Med. 2010;71(3):475-481.

58. Noseworthy DA, Phibbs SR, Benn CA. Towards a relational model of decision-making in midwifery care. Midwifery. 2013;29(7):e42-e48.

59. Conrad P. Medicalization and social control. Annual Review of Sociology. 1992;18:2019-232.

60. Gunson JS. More natural but less normal: Reconsidering medicalization and agency through women's accounts of menstrual suppression. Soc Sci Med. 2010;71(7):1324-1331.

61. Zola IK. Medicine as an institution of social control. Sociological Review. 1972;20(4):487-504.

62. Althabe F, Belizan JF. Caesarean section: The paradox. The Lancet. 2006;368(9546):1472-1473.

63. http://www.cdc.gov/nchs/data/nvsr/nvsr63/nvsr63_02.pdf

64. Vladeck BC, Fishman E. Health care, distributive justice, and the American political processes. Medicine and Social Justice. New York: Oxford University Press; 2012.

65. Sheehan H. Medicare in the USA: a review of 45 years of health provision. Indian J Med Ethics. 2011;8(3):164-166.

66. Tope D, Jacobs D. The politics of union decline: The contingent determinants of union recognition elections and victories. American Sociological Review. 2009;74(5):842-864. 
67. Prasad M. The politics of free market: The rise of neoliberal economic policies in Britain, France, Germany and the United States. Chicago, IL: University of Chicago Press; 2006.

68. Teghtsoonian K. Depression and mental health in neoliberal times: A critical analysis of policy and discourse. Soc Sci Med. 2009;69(1):28-35.

69. Minkler M. Personal responsibility for health? A review of the arguments and the evidence at century's end. Health Education \& Behavior. 1999;26(1):121-141.

70. Raphael D, Bryant T. The welfare state as a determinant of women's health: support for women's inequality of life in Canada and four comparison nations. Health Policy. 2004;68(1):63-79.

71. Amnesty International. Deadly delivery: The maternal health care crisis in the USA. London, UK: Amnesty International; 2010.

72. Institute of Medicine. Clinical preventive services for women: Closing the gaps. Washington, DC: The National Academies Press; 2011.

73. O'Campo P, Rojas-Smith L. Welfare reform and women's health: Review of the literature and implications for state policy. Journal of Public Health Policy. 1999;19(4):420-446.

74. Margolis L, Kotch JB. Tracing the historical foundations of maternal and child health to contemporary times. In: Jonathan B Kotch, editor. Maternal and child health. 3rd ed. Sudbury, MA: Jones \& Bartlett Learning; 2013.

75. Rosenfield A, Maine D. Maternal mortality - a neglected tragedy, where is the $\mathrm{M}$ in MCH? The Lancet. 1985;2(8446):83-85.

76. Lesser AJ. The origin and development of Maternal and Child Health programs in the United States. Am J Public Health. 1985;75(6):590-598.

77. Lemons JS. The Sheppard-Towner Act: Progressivism in the 1920's. The Journal of American History. 1969;55(4):776-786.

78. Scott-Samuel A, Bambara C, Hunter DJ, et al. The impact of Thatcherism on health and well-being in Britain. Int J Health Serv. 2014;44(1):53-71.

79. Wacquant L. Crafting the neoliberal state: Workfare, prisonfare, and social insecurity. Sociological Forum. 2010;25(2):197-220.

80. Katz M. In the shadow of the poorhouse: A social history of welfare in America. New York: Basic Books; 1996.

81. Katz MB. The undeserving poor: From the war on poverty to the war on welfare. New York: Pantheon; 1989.

82. Armentrout EG. An analysis of Adler's theory and the female criminal. University of North Texas; 2004:1-92.

83. Loxley W, Adams K. Women, drug use and crime: Findings from the Drug Use Monitoring in Australia program. Research and Public Policy no. 99; 2009 .

84. Boushey H, Gundersen B, Brocht C, et al. Hardships in America: The rea story of working families. Washington, DC: Economic Policy Institute; 2001.

85. Brauner S, Loprest P. Where are they now? What States' studies of people who left welfare tell us. Washington, DC: The Urban Institute; 1999.

86. Collins JL. The opposite of fordism: Wal-Mart rolls back a regime of accumulation. What's Wrong with America Conference; 2006:1-22.

87. Porter KH, Dupree A. Poverty trends for families headed by working single mothers:1993 to 1999. Washington, DC: Center on Budget and Policy Priorities; 2001.

88. Christopher K. Welfare state regimes and mothers' poverty. Luxembourg Income Study Working Paper. 2001;9(1):1-44.
89. Esping-Andersen G. The three worlds of welfare capitalism. Princeton, NJ: Princeton University Press; 1990.

90. Lewis J. Gender and welfare regimes: Further thoughts. Social Politics. 1997;4(2):160-177.

91. Sainsbury D. Gendering welfare states. London, UK: Sage Publications Ltd; 1994.

92. Bambra C. Going beyond the three worlds of welfare capitalism: Regime theory and public health research. Journal of Epidemiology \& Community Health. . 2007;61(12):1098-1102.

93. Borrel C, Palècia L, Muntaner C, et al. Influence of macrosocial policies on women's health and gender inequalities. Epidemiologic Reviews. 2014;36:31-48.

94. Link BG, Phelan J. Social conditions as fundamental causes of disease. $J$ Health Soc Beh 1995;35:80-94.

95. Link BG, Phelan JC. McKeown and the idea that social conditions are fundamental causes of disease. Am J Public Health. 2002;92(5):730-732.

96. Galea S, Tracy M, Hoggart KJ, et al. Estimated deaths attributable to social factors in the United States. Am J Public Health. 2011;101(8):1456-1465.

97. Cruikshank JK, Mbanya JC, Wilks R, et al. Sick genes, sick individuals or sick populations with chronic disease? The emergence of diabetes and high blood pressure in African-origin populations. Int J Epidemiol. 2001;30(1):111-117.

98. Stone D. Policy paradox: the art of political decision making, 2002. New York: Norton; 2002.

99. Agrawal P. Maternal mortality and morbidity in the United States of America. Bulletin of World Health Organization. 2015;93:135.

100. Chavkin W. Drug addiction and pregnancy: Policy crossroads. American Journal of Public Health. 1990;80(4):483-487.

101. http://www.euro.who.int/data/assets/pdf file/0004/76513/E92347. pdf?ua $=1$

102. Watt RG. From victim blaming to upstream action: Tackling the social determinants of oral health inequalities. Community Dentistry and Oral Epidemiology. 2007;35(1):1-11.

103. Association of State and Territorial Health Officials (ASTHO). State public healthemployee worker shortage report: A civil service recruitment and retention crisis. Washington, DC: ASTHO; 2004

104. Brennan T, Breitenbach M, Dieterich W, et al. Women's pathways to serious and habitual crime: a person-centered analysis incorporating gender responsive factors. Criminal Justice and Behavior. 2012;39:14811510 .

105. Brown LD. Exceptionalism as the rule? U.S. health policy innovation and cross national learning. Journal of Health Politics, Policy and Law. 1998;23(1):35-51.

106. Crane BB, Dusenberry J. Power and politics in international funding for reproductive health: the US Global Gag Rule. Reproductive Health Matters. 2004;12(24):128-137.

107. http://www.marxists.org/archive/marx/works/1845/conditionworkingclass/index.html

108. George S. Comments to the Congressional Black Caucus. 2000.

109. Henderson D. Drug abuse and incarcerated women. Journal of Substance Abuse Treatment. 1998;15(6):579-587.

110. Kruttschnitt C. The paradox of women's imprisonment. Daedalus Summer. 2010;139(3):32-42. 
111. Oliver TR. The politics of public health policy. Annual Reviews of Public Health. 2006;27:195-233.

112. Roux AVD. Integrating social and biologic factors in health research: A systematic view. Annals of Epidemiology. 2007.;17(7):569-574.

113. Sites E. Contesting the neoliberal city: Theories of neoliberalism and urban strategies contention. In: Leitner H, Peck J, Sheppard S, editors. Conflicting neoliberalism: Urban frontiers. New York: The Guildford Press; 2007.

114. Stuckler D. Population causes and consequences of leading chronic diseases: A comparative analysis of prevailing explanations. Milbank $Q$. 2008;86(2):273-326.
115. Thornton AJV, Graham-Kevan N, Archer J. Prevalence of women's violent and nonviolent behavior: a comparison of self-reports, victims' reports, and third party reports. J Interpersonal Viol. 2012;27(6):1399-1427 .

116. Van den Bergh BJ, Gatherer A, Fraser A, Moller L. Imprisonment and women's health: concerns about gender sensitivity, human rights, and public health. Bull World Health Organ. 2011;89(9):689-694.

117. Hoyert DL. Maternal mortality and related concepts. National Center for Health Statistics. Vital Health Statistics. 2007;3(33):20. 